\title{
Flexible Sustainable Supply Chain Network Design: Current Trends, Opportunities and Future
}

\author{
Angappa Gunasekaran $^{1} \cdot$ Rameshwar Dubey $^{2,3} \cdot$ Surya Prakash Singh ${ }^{4}$
}

Received: 1 April 2016/Accepted: 7 April 2016/Published online: 25 April 2016

(C) Global Institute of Flexible Systems Management 2016

\section{Introduction}

The present era is threatened due to fragile environment. Due to rapid change in climate and irresponsible consumption behaviors of human has led to natural resources scarcity and frequent natural disasters. The high degree of environmental uncertainty has attracted increasing attention from operations and supply chain management (O\&SCM) researchers. Hence, supply chain network design is considered to be of high importance among various operations and supply chain management strategies to address one of the greatest concerns of the human being of the century. Melnyk et al. (2014) have noted in one of their seminal works that supply chain design

Surya Prakash Singh

surya.singh@gmail.com

Angappa Gunasekaran

agunasekaran@umassd.edu

Rameshwar Dubey

rameshwardubey@gmail.com; rameshwar@ sustc.edu.cn

1 Charlton College of Business, University of Massachusetts Dartmouth, North Dartmouth, MA 02747-2300, USA

2 Symbiosis Institute of Operations Management, (Constituent of Symbiosis International University), Plot No. A-23, Shravan Sector, CIDCO, New Nashik 422008, India

3 Department of Electrical and Electronics Engineering, South University of Science and Technology of China, Room 302, Faculty Research Building 2, SUSTC, No. 1088 Xueyuan Blvd, Xili, Nanshan District, Shenzhen, China

4 Department of Management Studies, Indian Institute of Technology Delhi, Vishwakarma Bhawan, New Delhi, India problems are still underdeveloped and advocated for more comprehensive work towards development of sustainable and flexible supply chain network design. Similarly, the sustainable supply chain network design (SSND) though have attracted increasing attention from O\&SCM community, however, still most of the questions related to SSCND are unanswered or silent to the body of knowledge. The most of the existing literature on sustainable supply chain network stem from operations research (OR) angle, however, the social issues largely remains unanswered. Second, the flexibility issues in SSCND are also not very well addressed in the existing literature. The current literature mainly attempted to address from the manufacturing perspective, however, the sustainability and flexibility, and integration of both these aspects into a single SSCND largely remains unexplored. Boyer and Swink (2008) have also noted that the existing O\&SCM research lacks in multi-methods approach. However, multiple angles can help to take the current SSCND related research to a next level.

To address the existing research gaps, the special issue titled: Flexible Sustainable Supply Chain Network Design was organized by the guest editors. The current aim of the special issue was to attract scientific manuscripts which help to contribute to flexible sustainable supply chain network design literature and offers multiple solutions to those practitioners who are engaged in managing complex issues related to sustainable supply chain network design. In this special issue, six papers after rigorous double blind review process and Editor-inChief final inputs are finalized and each paper contributes towards the sustainable and flexible aspects in the network design of the supply chain which adds value to the existing body of knowledge. 


\section{Synoptic Overview of Selected Special Issue Papers}

The paper titled "An Integer Linear Program for Integrated Supplier Selection: A Sustainable Flexible Framework" authored by Kaur et al. was an attempt to develop a comprehensive model which addresses the pressing need for supplier selection using flexibility and sustainability as one of the two important criteria. Under flexibility factors such as production flexibility, responsiveness, after sale support and engineering support are considered. Similarly, under sustainability factors criteria are considered to account for people (social responsibility, quality certification and cultural differences), and planet (environment responsibility and carbon footprint) and profit (price of the product, financial health, tariff and taxes, logistics management cost). The paper conducted the survey on supplier selection of two continents i.e. Asia and Europe. Hence, the comprehensive approach proposed by Kaur et al. offers guidelines to many those organizations which are struggling to embrace flexible sustainable supplier selection approach. In addition to this, Kaur et al. also developed new Integer model to integrate various supplier rankings into a consolidated ranking. The consolidated rank is also compared with the Borda and Kendall (BAK) method, the oldest rank aggregation method (Cook and Seiford 1982), and they proved that the proposed integer linear model offers best aggregation rank as compared to Borda and Kendall (BAK) as it minimizes the total deviation of aggregated rank with respect to all individual ranks.

The second paper which is included in the special issue titled "Impediments to Social Sustainability Adoption in the Supply Chain: An ISM and MICMAC Analysis in Indian Manufacturing Industries" authored by Mani et al. In this paper, Mani et al. have attempted to address most important dimensions of sustainability (i.e. social sustainability) using interpretive structural modeling (ISM) technique. They also highlighted that the proposed framework in future can be further used as hypotheses to further develop theories surrounding social sustainability and flexibility in the overall network design of the supply chain.

The third paper titled "Integrated Forecasting Using the Discrete Wavelet Theory and Artificial Intelligence Techniques to Reduce the Bullwhip Effect in a Supply Chain" authored by Singh and Challa. Singh and Challa have attempted to address the bullwhip effect in supply chain network using discrete wavelet theory and artificial intelligence techniques. The findings of the study provide enough impetus for further research to address complex issues in supply chain design due to poor forecasting. The present work of the paper is a novel attempt where wavelet theory is integrated with the artificial intelligence in the design of supply chain network. The current body of knowledge on supply chain network design either applies wavelet theory or artificial intelligence, however, integration of these two is missing.

The fourth paper titled "Enablers and barriers of flexible green supply chain management: a Total Interpretive Structural Modeling approach" authored by Shibin et al. Shibin et al. attempted to build a theoretical framework of the enablers and barriers of flexible green supply chain management (FGSCM). The study conducted by them is unique in its kind and clearly illustrates both the enablers and barriers and their complex interrelationships that impact the design and implementation of flexible and green strategies in a network design of supply chain especially supply chain closed loop system. In this study, authors identified ten enablers and eight barriers of FGSCM through an extensive literature review process. Authors proposed separate framework for enablers and barriers of FGSCM using ISM and TISM approach.

The fifth paper titled "A review of RFID in supply chain management: 2000-2015" authored by Musa and Dabo. The paper presents a systematic literature review on radio frequency identification (RFID) in supply chain management between the years 2000 and 2015. As the literature on RFID is not confined to specific disciplines, the review paper proposes a discipline-based framework to classify RFID literature. Five main classification categories are used such as technology, supply chain management, research methodology, application industries, and social aspects. The paper nearly reviews 1187 articles appeared between 2000 and 2015 in top rated journals. The exhaustive review yields useful insights into the anatomy of RFID literature in network design of supply chain management and thus, enhances evidence-based knowledge, and contributes to informing practice, policymaking, and future research.

The sixth paper titled "Development Model of Cacao Agro-Industry with Sectoral Competitive Advantage Based in Southeast Sulawesi, Indonesia" authored by Hatani et al. The paper explores the development model of cacao industry with sectoral competitive advantage. The paper examines and explains the effects of market orientation, supply chain flexibility and strategic location towards competitive advantage in cacao industry. The practical implication provides information for decision makers of cacao industry in implementing market orientation, supply chain flexibility and market strategy by assessing the ability of partner supply chain to respond market fluctuations. 


\section{Conclusions and Future Research Directions}

This special issue will serve as a guidebook for designing flexible and responsive sustainable supply chain network. Since the design of supply chain network design involves selecting suitable partnering firms or suppliers, flexibility and responsiveness should be given due consideration for sustainable supply chain network design. The papers appear in the special issue deal with several aspects of supply chain network design with the objective of building flexibility and sustainability. However, there are still many issues which need to be addressed in order to design a flexible sustainable supply chain network. The following are some of the future research directions:

- Determine the criteria for selecting suitable suppliers or partnering firms which would result in flexible sustainable supply chain network.

- Sustainability should not only be viewed from the perspective of economic and environment, but social implications must be incorporated in supply chain network design.

- The role of IT/IS is critical in terms of automating the communication and in turn the integration of activities between a focal company and partnering firms.

- The role of big data and business analytics play a major role in global flexible sustainable supply chain network design. This needs further research on how to apply big data techniques for designing a global flexible and sustainable supply chain network.

- Suitable modeling and optimization techniques should be developed for designing an optimal sustainable supply chain network that is flexible and responsive to changing market or customer requirements.

- Suitable performance measures and metrics need to be developed for flexible sustainable supply chain network design and operations management.

- Determining the optimal number of suppliers or partners in a sustainable supply chain network design will significantly influence the performance and therefore, this needs further investigation.

- Exploring the role of simulation techniques in the design and management of flexible sustainable supply chain network design and operations needs due attention from researchers.

- Suitable mathematical programming models should be developed for flexible sustainable supply chain network incorporating the objective functions with appropriate constraints.
- The optimal workforce design is essential for flexible sustainable supply chain. However, this area did not receive adequate attention from researchers and practitioners.

Acknowledgments The Guest Editors of this special express their gratitude to all the authors who submitted their manuscripts and reviewers for their timely and critical feedback which helped to produce a quality special volume on flexible sustainable supply chain network design. This special issue would not have been a reality without the kind and generous support of Professor Sushil, the Editorin-Chief of the Global journal of Flexible Systems Management.

\section{References}

Boyer, K. K., \& Swink, M. L. (2008). Empirical elephants-why multiple methods are essential to quality research in operations and supply chain management. Journal of Operations Management, 26(3), 338-344.

Cook, W. D., \& Seiford, L. M. (1982). On the Borda-Kendall consensus method for priority ranking problems. Management Science, 28(6), 621-637.

Melnyk, S. A., Narasimhan, R., \& DeCampos, H. A. (2014). Supply chain design: Issues, challenges, frameworks and solutions. International Journal of Production Research, 52(7), 1887-1896.

\section{Key Questions}

1. Can proposed integer linear program for integrated supplier selection be integrated with mathematical model for supplier selection and order allocation?

2. How flexible sustainable supply chain network design can enhance the performance of supply chain network?

3. How the integrated forecasting using discrete wavelet theory and artificial intelligence techniques can reduce the bullwhip effect in supply chain network?

4. What are the various ways to manage barriers of flexible supply chain?

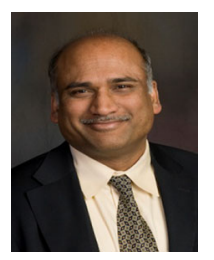

Dr. Angappa Gunasekaran is a Professor and Dean at the Charlton College of Business, University of Massachusetts, Dartmouth. Dr. Gunasekaran has held academic positions in UK, Australia, Finland, India and Canada. He has over 250 articles published in peer-reviewed journals. He has presented about 50 papers and published 50 articles in conferences and given a number of invited talks in many countries. He is on the Editorial Board of several journals. He has organized several international workshops and conferences in the emerging areas of operations management and information systems. He is currently interested in researching logistics and supply chain management. Dr. Gunasekaran has been the founding Director of Business Innovation Research Center (BIRC) since 2006. 


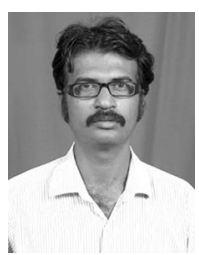

Dr. Rameshwar Dubey is an academician with rich post-doctoral experience in the field of sustainable operations and humanitarian operations management. He is currently working as a visiting Professor and Research Fellow at SUSTC, Shenzen at Big Data Research Centre and Associate Professor (on leave) with Symbiosis International University and associated with various institutions of repute as a visiting scholar which includes institutes of national importance and some global universities like DePaul University and Anhui University of Finance and Economics, China. Besides teaching post-graduate students and doctoral students, he has conducted several faculty development programs and management development programs for Public sector Units and other reputable organizations. At present he is serving as a guest editor with over twelve reputable journals published by Elsevier, Springer, Inderscience, Taylor \& Francis and IGI. His current research interest's lies in explaining complex supply chain phenomena using "big data" along with his colleagues from five countries situated in USA, Europe and Asia. He has published over 60 papers indexed in Scopus and SCI/SSCI Journals with over 170 citations.

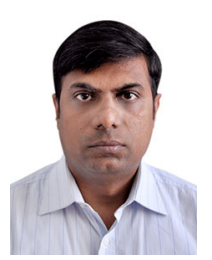

Dr. Surya Prakash Singh is an Associate Professor in the Department of Management Studies, I.I.T. Delhi, India. He holds a PhD from I.I.T. Kanpur. He is also a Post-Doctoral Fellow from NUS Singapore-MIT USA Alliance. His research interest areas are facility layout problems, Heuristics, Meta-heuristics, modeling operations and supply chain management, and optimizing operations using big-data. He has published over 80 research papers. His work has been published in leading international journals such as IJPR, LNCS, IJAMT, EJM, RBR, IJRTE, and APMR. He regularly reviews articles for many leading journals. His biography appeared in Marquis, USA Who's Who in Science and Engineering, December 2007, and Who's Who in the World, November 2010. Recently, he has been awarded Young Outstanding Faculty Fellowship from I.I.T. Delhi. 